\title{
Nurse-patient interaction and self- transcendence: assets for a meaningful life in nursing home residents?
}

\author{
Gørill Haugan ${ }^{1,2^{*}}$, Britt Moene Kuven ${ }^{3}$, Wenche Mjanger Eide ${ }^{3}$, Siv Eriksen Taasen ${ }^{3}$, Eva Rinnan ${ }^{1,4}$, Vivien Xi Wu ${ }^{5}$,
} Jorunn Drageset ${ }^{3,6}$ and Beate André

\begin{abstract}
Background: Due to the shift to an older population worldwide and an increased need for 24-h care, finding new and alternative approaches to increase wellbeing among nursing home $(\mathrm{NH})$ residents is highly warranted. To guide clinical practice in boosting wellbeing among NH residents, knowledge about nurse-patient interaction (NPI), inter- (ST1) and intra-personal (ST2) self-transcendence and meaning-in-life (PIL) seems vital. This study tests six hypotheses of the relationships between NPI, ST1, ST2 and PIL among cognitively intact NH residents.

Methods: In a cross-sectional design, 188 (92\% response rate) out of 204 long-term NH residents representing 27 NHs responded to NPI, ST, and the PIL scales. Inclusion criteria were: (1) municipality authority's decision of longterm NH care; (2) residential time 3 months or longer; (3) informed consent competency recognized by responsible doctor and nurse; and (4) capable of being interviewed. The hypothesized relations between the latent constructs were tested through structural equation modeling (SEM) using Stata 15.1.

Results: The SEM-model yielded a good fit $(X 2=146.824, p=0.021, \mathrm{df}=114, \mathrm{X} 2 / \mathrm{df}=1.29$ RMSEA $=0.040, \mathrm{p}$-close $0.811, \mathrm{CFI}=0.97, \mathrm{TLI}=0.96$, and SRMR $=0.063$ ), supporting five of the six hypothesized relationships between the constructs of NPI, ST1, ST2 and PIL.

Conclusion: NPI significantly relates to both ST1, ST2 and PIL in NH residents. ST revealed a fundamental influence on perceived PIL, while NPI demonstrated a significant indirect influence on PIL, mediated by ST.
\end{abstract}

Keywords: Interpersonal and intrapersonal self-transcendence, Meaning-in-life, Nursing, Nurse-patient interaction, Nursing home, Older adults, Wellbeing

\section{Background}

Currently, the world faces a rapidly aging population. The document An Aging World [1] highlights a shift to an older population worldwide and its consequences: the population aged $80+$ grows faster than any younger age group, and those aged 100+ are growing fastest [2]. This

\footnotetext{
* Correspondence: gorill.haugan@ntnu.no

'Department of Public Health and Nursing, Faculty of Medicine and Health Science, NTNU Norwegian University of Science and Technology, Trondheim, Norway

${ }^{2}$ NORD University, Faculty of Nursing and Health Science, Levanger, Norway Full list of author information is available at the end of the article
}

shift started in high-income countries. However, today most people in the world can expect to live into their sixties and beyond [3]. During the period from 2015 and 2050 , the proportion of those 60 years and more will nearly double from 12 to $22 \%$; by 2050 , individuals aged 60 years and older is expected to total 2 billion, up from 900 million in 2015 [1, 3]. Currently, low- and middleincome countries are experiencing the greatest demographic change; hence, all countries are now facing major challenges to ensure that their health and social

C C The Author(s). 2020 Open Access This article is licensed under a Creative Commons Attribution 4.0 International License, which permits use, sharing, adaptation, distribution and reproduction in any medium or format, as long as you give appropriate credit to the original author(s) and the source, provide a link to the Creative Commons licence, and indicate if changes were made. The images or other third party material in this article are included in the article's Creative Commons licence, unless indicated otherwise in a credit line to the material. If material is not included in the article's Creative Commons licence and your intended use is not permitted by statutory regulation or exceeds the permitted use, you will need to obtain permission directly from the copyright holder. To view a copy of this licence, visit http://creativecommons.org/licenses/by/4.0/ The Creative Commons Public Domain Dedication waiver (http://creativecommons.org/publicdomain/zero/1.0/) applies to the data made available in this article, unless otherwise stated in a credit line to the data. 
systems are ready to make the most of this demographic shift [3].

As longevity is increasing worldwide, it is important to ensure that the extra years of life are worth living, despite chronic illnesses. However, still evidence do not suggest that older people today are experiencing their later years in better health than their parents $[4,5]$. Increased age is followed by an increased incidence of functional and chronic comorbidities and diverse disabilities [6]. Hence, a noteworthy part of older adults will need 24-h nursing home $(\mathrm{NH})$ care. In Norway, about $7.2 \%$ of the people older than 67 years and $9.1 \%$ of those older than 80 years live their last phase of life in NHs; mean residential time is about $1-2$ years [7, 8], and about $30-40 \%$ of deaths annually in the US and Norway happen in NHs $[8,9]$. Hence, the NH population is characterized by high age, frailty, chronic illnesses, multiple diagnoses, mortality, disability, powerlessness, dependency, vulnerability, poor general health and a high symptom burden [10-12]. Healthpromotive initiatives enhancing wellbeing among older persons living in NHs will become ever more important in the years to come.

Accordingly, relocating to a $\mathrm{NH}$ is caused by numerous losses, illnesses, disabilities, loss of functions and social relations, and facing the end-of-life, all of which increases an individual's vulnerability and distress. Loneliness and depression are identified as risks to older people's emotional wellbeing [13-15]. Consequently, this population is at a high risk of declined meaning-in-life and wellbeing $[16,17]$; thus, finding new and alternative approaches to increase wellbeing among older adults in NHs is highly warranted.

Spirituality has been perceived as a major resource for wellbeing in late life [18], particularly among frail and vulnerable older people such as $\mathrm{NH}$ residents [19]. As an essential aspect of spirituality, the concept of meaning-in-life is commonly addressed in the nursing literature [20] and is seen to be of importance to wellbeing in older adults [17, 18, 21, 22], in NHs [23-25], and at the end of life [26-28]. Research implies that perceived meaning-in-life is important for maintaining not only mental/emotional wellbeing, but physical and functional wellbeing as well $[11,29]$. A novel study demonstrates humans' holistic existence showing that life meaning as well as loneliness affected older adults' brain function [30]. These findings advance our understanding of phenomena such as meaning-in-life and loneliness which operate not only by emotions or experiences but represent physical states in the human brain (ibid.).

Social relationships imbue life with meaning, whereas loneliness diminishes one's sense of meaning-in-life. The 'search for meaning and finding answers', 'feelings of support and trust', 'a perspective beyond death' [19], along with a sense of belonging [31-34] are fundamental to perceived meaning-in-life, spiritual-emotional wellbeing [35, 36] and life satisfaction [37] in older adults. Perceived meaning-in-life is seen to predict life satisfaction among $\mathrm{NH}$ residents [38].

Additional to meaning-in-life, the concept of selftranscendence addresses an enhanced understanding of wellbeing in late adulthood [39, 40] and among different vulnerable populations, such as $\mathrm{NH}$ residents, cancer and AIDS patients as well as homeless individuals (ibid.). The human developmental theory emphasises maturity as the developmental task across the life-span [41]; self-transcendence is defined as a "characteristic of developmental maturity wherein there is enhanced awareness of the environment and an orientation toward broader life perspectives" [39]. Self-transcendence is salutogenic; it is conceptualized as an inherent resource for wellbeing, particularly in challenging health conditions including end-of-life. Nursing's role is to describe, explain, and facilitate these processes as they occur in human beings during health experiences and events across the lifespan [40]. Further, self-transcendence is seen to be a powerful coping mechanism involving adaption to physical, emotional and spiritual distress, leading to personal transformation, maturity and wellbeing. Selftranscendence is positively related to mental/emotional wellbeing, health and functioning in adults confronting personal mortality because of advanced age and/or enduring illness [42-46]. Connectedness is the core of self-transcendence $[39,40]$.

The experience of connectedness for older people in long-term care settings is linked with quality-of-life (QoL) and successful aging [47]. Research has shown that self-awareness, meaningful relationships with family and friends, involvement in meaningful activities and connections with wider society are fundamental prerequisites of connectedness for older people [47]. However, barriers to these prerequisites are evident for many residents in long-term care settings [47]. Largely, the nursepatient relationship represents the main resource for connectedness while staying in an $\mathrm{NH}$. Therefore, the nurse-patient interaction might be crucial for wellbeing in NHs. Self-transcendence and meaning-in-life have demonstrated significant relations with both physical, emotional, social, functional $[29,48]$ and spiritual [49] wellbeing among cognitively intact $\mathrm{NH}$ residents, indicating that enhancing self-transcendence and meaningin-life positively influences on all aspects of wellbeing.

To summarise, the literature suggests that nursepatient interaction, self-transcendence, and meaning-inlife are vital to wellbeing among older adults in NHs. Thus, we expected meaning-in-life and selftranscendence to be correlated, and that nurse-patient 
interaction would influence on both constructs. To get further insights into how self-transcendence and meaning-in-life relate with each other, as well as with nurse-patient interaction, this study investigates the associations between nurse-patient interaction, selftranscendence and perceived meaning-in-life. Such knowledge can guide clinical practice in how to best and efficiently boost wellbeing among older adults in NHs.

\section{Aims and hypotheses}

The present study was therefore designed to investigate the relationships between nurse-patient-interaction, selftranscendence and meaning-in-life among cognitively intact $\mathrm{NH}$ residents utilizing structural equation modeling (SEM). The research questions were: (1) Does the nursepatient interaction affect interpersonal selftranscendence (ST1), intrapersonal self-transcendence (ST2) and meaning-in-life in cognitively intact NH residents? and (2) How do the constructs of ST1, ST2 and meaning interrelate?

Psychometric studies have revealed a two-factor construct (ST1, ST2) showing the best fit for selftranscendence [50], whereas nurse-patient interaction [51] is found to be a one-dimensional construct. Thus, the two-factor construct of self-transcendence (where ST1 embraces interpersonal aspects whereas ST2 covers intrapersonal aspects) along with the one-factor models of nurse-patient interaction [51] and meaning-in-life (PIL) [52] were applied in the present study. Based on the theoretical and empirical knowledge of nurse-patient interaction, self-transcendence (ST) and meaning-in-life, the following hypotheses were formulated:
Hypothesis 1 (H1): Nurse-patient interaction positively affects ST1 (Inter-personal ST).

Hypothesis 2 (H2): Nurse-patient interaction positively affects ST2 (Intra-personal ST).

Hypothesis 3 (H3): Nurse-patient interaction positively and directly affects meaning-in-life (PIL).

Hypothesis 4 (H4): Nurse-patient interaction indirectly affects meaning-in-life (PIL).

Hypothesis 5 (H5): ST1 positively affects PIL.

Hypothesis 6 (H6): ST2 positively affects PIL.

A hypothesized structural equation model (SEM) with bases in existing theory $[39,40,53,54]$ and previous empirical research $[29,31,48,55]$ was tested. Figure 1 shows the hypotheses representing the relationships implying the influences between the latent constructs in the model. Significant associations have been demonstrated between nurse-patient-interaction and selftranscendence [51] and meaning [36]. H1-H4 in Fig. 1 reflects the hypothesized associations between nursepatient interaction, self-transcendence and meaning. ST1 and ST2 involve aspects such as having interests and hobbies, involving and caring for others (ST1), adapting well and self-acceptance (ST2); hence, these dimensions were hypothesized to associate with meaning-in-life (PIL), shown as hypotheses $\mathrm{H} 5$ and $\mathrm{H} 6$ in Fig. 1.

By doing so, we pursued contributing to a nursing perspective of promoting the wellbeing of older adults in NHs in three ways. First, research focusing on the dimensions of self-transcendence, meaning and nursepatient interaction in NHs is scarce [56]. The healthpromoting magnitude of these dimensions to older

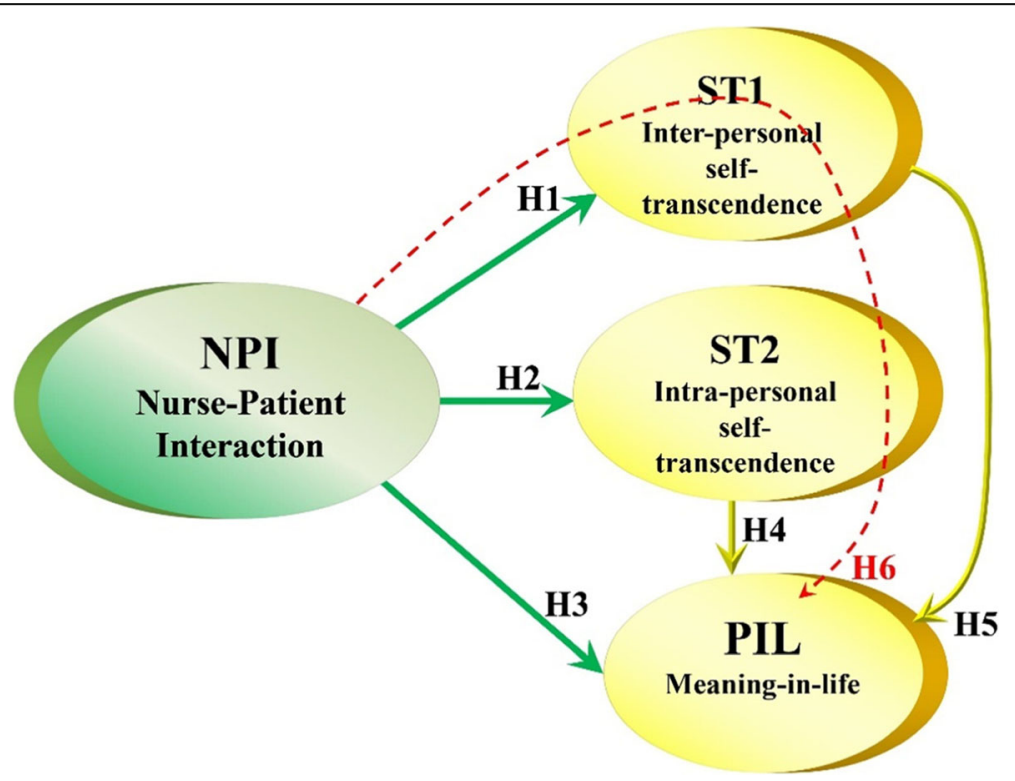

Fig. 1 Hypotheses tested 
adults and $\mathrm{NH}$ patients has recently been identified [31, 38, 57-59], the fundamental relationships between nurse-patient-interaction, self-transcendence and meaning in $\mathrm{NH}$ residents are scarcely documented, though. Second, examining the associations between self-transcendence and meaning contributes to a deepened theoretical understanding of how nursing care can boost $\mathrm{NH}$ residents' wellbeing. Accordingly, this study provides more specific insights about the mechanisms involved in the relationships between these vital dimensions, as well as on nurse-patient interaction's associations to them. As self-transcendence and meaning are found to be interwoven with individuals' health and wellbeing [60-62], nurse-patient interaction might influence not only on $\mathrm{NH}$ residents' emotional and social wellbeing, but also on their physical wellbeing [48, 63-67].

\section{Methods \\ Participants}

For running SEM-analyses, large samples of $N \geq 200$ are recommended [68-71]. Thus, the present sample consisted of $188(92.0 \%)$ out of 204 long-term $\mathrm{NH}$ residents, residing in $27 \mathrm{NHs}$, located in two small and one large urban municipality in Mid-Norway $(N=88$, living in Joy-of-Life Nursing Homes (JoLNH); these are NHs which have undergone a certification process of 1-2 year working on meeting the residents social, cultural and spiritual needs [72], along with a large urban municipality in Western Norway $(N=100$, ordinary NHs which are not certified as a JoLNH). Long-term $\mathrm{NH}$ care was termed as 24-h care. Exclusion criteria were short-term care, rehabilitation stay, and diagnosed with dementia. Inclusion criteria were as follows: (1) municipality authority's decision of long-term $\mathrm{NH}$ care, (2) residential stay of 3 months or more (the reason for this was two-fold; 1) moving to an $\mathrm{NH}$ represents stress and is found to be demanding; therefore, we did not want to interrupt asking many questions about wellbeing, joy-of-life, meaning-in-life, etc. during this vulnerable phase, and 2) before replying to the questionnaire the residents need some experience of the inhouse life in an $\mathrm{NH}$. Thus, we wanted the resident to have stayed for 3 months or more), (3) informed consent competency recognized by responsible doctor and nurse, and (4) capable of taking part adequately in an interview situation.

\section{Procedures}

Cross-sectional data were collected during 2017 and 2018. The Regional Committee for Medical and Health Research Ethics in Norway (ref.nr 2014/2000/REK Central) as well as the Management Units at the $27 \mathrm{NHs}$ approved the study. The participants provided voluntarily written informed consent. A nurse who the $\mathrm{NH}$ residents knew well presented them with oral and written information about their rights as participants and their rights to withdraw at any time. Each participant provided informed consent. This population may have difficulties completing a questionnaire on their own. Therefore, six trained researchers (three in each part of Norway) conducted one-on-one interviews in private. Researchers with an identical professional background (RN, MSc, trained and experienced in communication with the elderly, as well as teaching gerontology at an advanced level) were trained to conduct the interviews in the same manner. To avoid misunderstandings, interviewers read each question loudly, and held a large-print copy of questions and possible responses in front of the participants. This study is part of the project Health promotion factors in Joy-of-Life Nursing Homes funded by the Norwegian Research Council. This project aimed to explore health promotion factors in Norwegian NHs, including certified JoLNHs and ordinary NHs. Accordingly, the three scales used in this study were part of the larger questionnaire comprising 9 scales representing 120 items as well as sociodemographic data (age, gender, marital status, residential time in the $\mathrm{NH}$ ); thus, small breaks at specific points during the interview process were adopted to avoid tiring the participants. The nine scales were assessed in the following order; 1 . Health-related QoL assessing symptom burden, 2. Joy-of-life, 3. a single item assessing loneliness, 4 . Sense of coherence, 5 . Self-transcendence, 6. Meaning-in-life, 7. Nurse-patient interaction, 8. Depression and anxiety, and 9. OPQOLbrief quality-of-life questionnaire. The OPQOL-brief data were recently published in a study testing the psychometric properties of the Norwegian version of OPQOL-brief [73]. Similarly, the Joy-of-Life scale was psychometrically tested, and used in a study assessing the associations between Nurse-Patient Interaction and joy-of-life [74] in the sample which is used for the present study.

\section{Measures}

The Nurse-Patient-Interaction Scale (NPIS) was developed in Norway to assess the vital characteristics of $\mathrm{NH}$ residents' experiences of the nurse-patient interaction [51]. The NPIS 14 items assess NH resident's ability to obtain a sense of wellbeing from essential relational and caring qualities embedded in the nurse-patient interaction. The term 'nurse-patient interaction' covers $\mathrm{NH}$ residents' perceived interaction with their professional caregivers in the $\mathrm{NH}$; these professionals are nurses (RNs), Licensed Nurse Assistants (LNAs) and caregivers without any formal education in health care. The NPIS is a 10-point scale from 1 (not at all) to 10 (very much); 
higher numbers indicate that residents perceive better nurse-patient-interaction. Examples of NPIS-items include the experience of being taken seriously, and being understood, respected, and recognized as a person, as well as being listened to and feeling good resulting from the nurse-patient-interaction. The items were developed to measure $\mathrm{NH}$ residents' ability to derive a sense of wellbeing through the nurse-patient-interaction. The NPIS has shown good psychometric properties with good construct validity and reliability among $\mathrm{NH}$ residents [51].

Self-transcendence was assessed by the SelfTranscendence Scale (STS), developed in the U.S. to identify experiences of later life and reflecting expanded boundaries of the self $[39,75]$. The STS comprises 15 items rated on a 4-point Likert-type scale from 1 (not at all) to 4 (very much); higher scores indicate higher selftranscendence. The STS was translated into Norwegian and validated among $\mathrm{NH}$ residents, showing a twofactor construct of self-transcendence [50], which is used for the present study. The items 'Having hobbies or interests I can enjoy', 'Involving in others' and 'Sharing my wisdom', were indicators for interpersonal selftranscendence (ST1). Test items for intrapersonal selftranscendence (ST2) were 'Accepting myself as I grow older', 'Adjusting well to my present life situation' and 'Adjusting to changes in my physical abilities'. In former studies, Cronbach's $\alpha$ for the total scale ranges between 0.80-0.88 [76-78].

The Purpose-in-Life-Test (PIL) was designed to assess meaning-in-life and is commonly used for this purpose [79-81]. The PIL contains 20 items which are based on Frankl's logotherapy [82-84]. Test items include questions such as 'My life is: empty, filled only with despair - running over with exciting things' and 'In thinking of my life, I: often wonder why I exist - always see reasons for being here.' Each of the 20 statements is scored from 1 to 7 where 4 represents a neutral value; whereas the numbers from 1 to 7 stretch along a continuum from one extreme feeling to the opposite kind of feeling. The range of possible scores is 20-140; numerically higher scores indicate greater meaningfulness [82]. The PIL was translated into Norwegian by Bondevik [85] and has previously been used and validated with older adults showing good psychometric properties [52, 86-88].

\section{Statistical analysis}

The data were analyzed by descriptive statistics using IBM SPSS version 25. The hypothesized relations between the latent constructs of NPIS, ST1, ST2 and PIL were tested through a structural equation model (SEM) using Stata 15.1 [89]. Using SEM accounts for random measurement error and the psychometric properties of the scales involved are more accurately derived. Missing data was low in frequency and were handled employing the listwise procedure. Research has indicated that Cronbach's $\alpha$ cannot be generally relied on as an estimator of reliability [90]. Thus, composite reliability was estimated using the formula by Hair and colleagues [70], as shown in Table 2; a coefficient of $\geq 0.7$ is good whereas 0.6 is considered fair for both reliability coefficients [77, 79, 82, 83]. For the correlation analyses, the $p$-value was set to $1 \%$, whereas the estimates based in SEM-analyses commonly include both 5 and $1 \% p$-values. Factor loadings below 0.32 are considered poor, $\geq 0.45$ fair, $\geq 0.55$ good, $\geq 0.63$ very good, and above 0.71 are excellent [91].

\section{Model fit}

In line with the rule of thumb of conventional cut-off criteria [92] the following fit indices were used to evaluate model fit: chi-square $\left(x^{2}\right)$ and its $p$-value which is significant in most cases. Therefore, instead of solely considering the $p$-value, it is suggested to consider the value of $\mathrm{X}^{2} /$ degrees of freedom (df), which should be $\leq 2$ for good fit and $\leq 3$ for an acceptable fit [93]. Since skewness and kurtosis were significant, the Satorra-Bentler-scaled chi-square statistic is the correct asymptotic mean and was therefore applied as a goodness-of-fit statistic [94]. However, the $X^{2}$ statistic is sensitive to sample size and is therefore not relied upon as a basis for acceptance or rejection of the model $[92,95]$. As a result, the use of multiple fit indexes has developed to provide a more holistic view of the goodness of fit, taking account not only of sample size but also of model complexity and other relevant issues of the study. Further, the root mean square error of approximation (RMSEA) and the standardized root mean square residual (SRMS) with values below 0.05 indicating good fit, whereas values smaller than 0.08 are interpreted as acceptable [92, 96]. Also, the comparative fit index (CFI) and the Tucker Lewis Index (TLI) were used with an acceptable fit at $0.95 / 0.90$ respectively, and good fit at 0.95/0.97 and above (ibid.).

Before examining the hypothesized relationships, the measurement models were tested by confirmatory factor analysis (CFA) using Stata 15.1 [89]. An appropriate power analysis is dependent on the ratio between the total number of variables (error measurements, observed and latent variables) and the sample size; one observed variable per 10 participants is given as a rule of thumb $[68,69,71]$. Thus, to reduce model complexity, the measurement model for nurse-patient-interaction was tested by CFA; by considering the loadings, $\mathrm{R}^{2}$-values (items which explain very little of the factor is dismissed) as well as covering the breadth and nuances of the actual construct, the indicator variables were reduced to six for NPIS $\left(x^{2}=8.850, p=0.451, d f=9\right.$, RMSEA $=0.000, p-$ 
close $0.748, \mathrm{CFI}=1.00, \mathrm{TLI}=1.00, \mathrm{SRMR}=0.021$ ), while meaning-in-life $\left(x^{2}=5.066, p=0.408, \mathrm{df}=5\right.$, RMSEA $=$ 0.008, $\mathrm{p}$-close 0.643, CFI $=0.999, \mathrm{TLI}=0.999, \mathrm{SRMR}=$ 0.030 ), were represented by five indicators. Furthermore, for the ST-construct $\left(\chi^{2}=3.886, p=0.867, \quad \mathrm{df}=8\right.$, RMSEA $=0.000, p$-close 0.961, CFI $=1.00, T L I=1.00$, SRMR $=0.022$ ) the three-indicator rule [70] was applied, including three indicators for ST1 and ST2, respectively, (totally six indicators). Consequently, the total number of indicators included in the SEM-model was $17(6+5+$ $3+3)$.

\section{Results}

\section{Descriptive analysis}

The 188 participants' ages ranged between 63 and 104 years, with a mean age of 87.4 years $(\mathrm{SD}=8.57)$. With 8 missing, the effective sample was $N=180$, consisting of 132 women (73.3\%) and 48 men (26.7\%). The mean age for women was 88.3 years $(\mathrm{SD}=1.80)$ and 86 years $(\mathrm{SD}=$ 1.16) for the men. In total, 23 were married, 22 cohabitating, 1 was single, 106 were widows/widowers, and 36 were divorced. Table 1 displays the means (M), standard deviations (SD), Cronbach's $\alpha$, and Pearson's correlation matrix for the latent study variables. The correlations between the measures were in the expected direction. Moderate correlations were found between the latent constructs (Table 1). The $\alpha$-levels for the various measures indicate an acceptable level of inter-item consistency with Cronbach's alpha coefficients ranging between 0.63-0.88 [97]; however, ST1 and ST2 comprised only three items each and consequently displayed a lower $\alpha$ coefficient of .63 (Table 1).

\section{Model testing and model fit SEM-analyses}

To investigate how the nurse-patient-interaction related to ST1, ST2 and meaning, as well as how the dependent latent variables were inter-related, a SEM-model comprising 17 indicators was estimated. For scaling the variances of the dependent latent variables were set at 1 . Table 2 lists the measurement models with factor loadings, $\mathrm{t}$-values, $\mathrm{R}^{2}$-values, and composite reliability. All factor loadings were significant, showing fair to good estimates ranging from 0.48 to 0.87 , with $\mathrm{R}^{2}$-values between 0.23 and 0.76 . Composite reliability ranged between 0.63-0.80, with ST1 and PIL showing the lowest coefficients of 0.63 and 0.64 , respectively (Table 2 ).

Figure 2 portrays the SEM-model showing the structural regression coefficients and the fit indices.

The SEM-model yielded a good fit to the data $\left(\mathrm{X}^{2}=\right.$ 146.824, $p=0.021, \quad \mathrm{df}=114, \quad \chi^{2} / \mathrm{df}=1.29$ RMSEA $=$ $0.040, \quad$ p-close $0.811, \quad$ CFI $=0.97, \quad T L I=0.96$, and SRMR $=0.063$ ). Table 3 shows the standardized regression coefficients of the directional relationships, as well as the total and indirect effects between the latent constructs in the SEM-model. According to Fig. 2, the hypotheses $\mathrm{H} 1$ and $\mathrm{H} 2$ were significant showing directional paths from nurse-patientinteraction to ST1 $(\gamma 1,1=0.41)$ and ST2 $(\gamma 2,1=0.43)$, while the path from NPIS on PIL (H3) was not significant. Furthermore, the direct relationships (Table 3 ) between the dependent variables, as assumed in $\mathrm{H} 5$ and $\mathrm{H} 6$ displayed significant values from ST1 to PIL $(\beta 1,3=0.56)$ and from ST2 to PIL $(\beta 2,3=0.30)$. Looking at the indirect influences (Table 3, Fig. 2), nurse-patient-interaction revealed a significant indirect effect on PIL (H4), mediated by ST1 and ST2 (0.34, total effect 0.37 ) (Table 3). Thus, the hypotheses H1, H2, H4-H6 were supported.

\section{Discussion}

The present study aimed to explore 1) the influences of NPIS on ST1, ST2, and PIL, and 2) the associations between ST1 and ST2 on PIL in cognitively intact NH residents. Among the six hypotheses tested five were supported at the 5\%-level. We could show significant associations between NPIS on ST1, ST2 as well as a mediated association on PIL. Additionally, our results showed a statistically significant association between ST1 and ST2 on PIL.

\section{Nurse-patient-interaction relates to self-transcendence and meaning-in-life}

More specifically, a significant impact of nurse-patientinteraction on interpersonal (ST1), intrapersonal selftranscendence (ST2) and meaning-in-life was found, as well as a significant indirect relation to meaning-in-life, mediated by self-transcendence (ST1, ST2).

Table 1 Mean, Cronbach's alpha, and correlation coefficients for the study variables

\begin{tabular}{lllllll}
\hline Construct & Mean $(\mathrm{sd})$ & Items & Cronbach's Alpha & ${ }^{{ }^{a} S T 1}$ & ${ }^{\text {b ST2 }}$ & ${ }^{\text {CPIL }}$ \\
\hline ST1 & $2.54(.711)$ & 3 & 0.63 & 1 & & \\
ST2 & $3.20(.675)$ & 3 & 0.78 & $.26^{* *}$ & 1 & \\
PIL & $4.11(.613)$ & 5 & 0.71 & $.37^{* *}$ & $.27^{* *}$ & 1 \\
NPIS & $7.98(1.91)$ & 6 & 0.88 & $.30^{* *}$ & $.33^{* *}$ & $.19^{* *}$ \\
\hline
\end{tabular}

** $p$-value $<0.01,{ }^{a} S T 1$ Interpersonal self-transcendence, ${ }^{\mathrm{b}} S T 2$ Intrapersonal self-transcendence, ${ }^{c} P I L$ Meaning-in-life, ${ }^{\mathrm{d}} N P I S$ Nurse-Patient Interaction. Listwise $N=$ 180, Missing $N=8$ 
Table 2 Measurement models for Nurse-Patient Interaction (NPIS), Self-transcendence (ST1 and ST2) and Meaning-in-Life (PIL)

\begin{tabular}{|c|c|c|c|c|}
\hline Items & Parameter & Stata Estimate ${ }^{\mathbf{b}}$ & t-value & Bentler-Raykov squared multiple correlation ${ }^{c} R^{2}$ \\
\hline \multicolumn{5}{|c|}{ NPIS Nurse-Patient Interaction } \\
\hline${ }^{\mathrm{e}} \mathrm{NPIS3}$ & $\lambda \times 3,1$ & 0.80 & $24.80^{a}$ & 0.64 \\
\hline NPIS4 & $\lambda \times 4,1$ & 0.73 & $18.16^{\mathrm{a}}$ & 0.53 \\
\hline NPIS5 & $\lambda \times 5,1$ & 0.77 & $21.23^{\mathrm{a}}$ & 0.58 \\
\hline NPIS11 & $\lambda \times 11,1$ & 0.79 & $23.79^{\mathrm{a}}$ & 0.63 \\
\hline NPIS13 & $\lambda \times 13,1$ & 0.84 & $28.89^{\mathrm{a}}$ & 0.70 \\
\hline NPIS14 & $\lambda \times 14,1$ & 0.52 & $08.90^{\mathrm{a}}$ & 0.27 \\
\hline \multicolumn{5}{|c|}{ ST1 Interpersonal Self-Transcendence } \\
\hline${ }^{\mathrm{f}} \mathrm{ST} 1$ & $\lambda \times 1,2$ & 0.56 & $7.64^{\mathrm{a}}$ & 0.31 \\
\hline ST3 & $\lambda \times 3,2$ & 0.56 & $7.94^{\mathrm{a}}$ & 0.31 \\
\hline ST6 & $\lambda \times 6,2$ & 0.72 & $10.81^{\mathrm{a}}$ & 0.52 \\
\hline \multicolumn{5}{|c|}{ ST2 Intrapersonal Self-Transcendence } \\
\hline ST2 & $\lambda \times 2,3$ & 0.54 & $8.89^{\mathrm{a}}$ & 0.29 \\
\hline ST4 & $\lambda \times 4,3$ & 0.87 & $20.32^{\mathrm{a}}$ & 0.76 \\
\hline ST5 & $\lambda \times 5,3$ & 0.82 & $18.49^{\mathrm{a}}$ & 0.67 \\
\hline \multicolumn{5}{|c|}{ PIL Meaning-in-life } \\
\hline${ }^{9} \mathrm{PIL} 5$ & $\lambda y 11,2$ & 0.48 & $6.46^{\mathrm{a}}$ & 0.23 \\
\hline PIL8 & $\lambda y 11,2$ & 0.49 & $6.51^{\mathrm{a}}$ & 0.24 \\
\hline PIL10 & $\lambda y 12,2$ & 0.53 & $7.23^{\mathrm{a}}$ & 0.29 \\
\hline PIL18 & $\lambda y 11,2$ & 0.54 & $7.76^{\mathrm{a}}$ & 0.30 \\
\hline PIL20 & $\lambda y 13,2$ & 0.54 & $7.60^{\mathrm{a}}$ & 0.29 \\
\hline${ }^{\mathrm{d}} \rho_{c} \mathrm{ST} 1$ & ${ }^{\mathrm{d}} \rho_{c}$ & 0.63 & & \\
\hline$\rho_{c} \mathrm{ST} 2$ & $\rho_{c}$ & 0.80 & & \\
\hline$\rho_{c} \mathrm{PIL}$ & $\rho_{c}$ & 0.64 & & \\
\hline$\rho_{c} \mathrm{NPIS}$ & $\rho_{c}$ & 0.89 & & \\
\hline
\end{tabular}

Our results showed that NPIS seems to have an outstanding position as a resource for ST1, ST2 and meaning-in-life in this vulnerable population. However, the influence on PIL was mediated by ST1 and ST2, indicating that to facilitate $\mathrm{NH}$ residents' meaning-in-life, health professionals should support ST1 and ST2. Previous research underlines that $\mathrm{NH}$ residents' perceived nurse-patient interaction is critical to their sense of dignity, self-respect, feelings of self-worth, meaning-in-life, and wellbeing [33, 36, 59, 98-100]. NPIS covers aspects such as being taken seriously, being understood, respected and recognised as a unique person; all of which relate closely to a sense of dignity, as well as a sense of self-worth and self-respect. Resulting from their frailty, vulnerability and dependency, $\mathrm{NH}$ residents stress their need for connectedness or belongingness with the nurses [31-33, 101, 102] highlighting the relationships to their caregivers as essential for wellbeing [103, 104].
Moreover, dignity significantly predicts older adults' satisfaction with $\mathrm{NH}$ staff [38] and has been related to the nurse-patient relationship [33]. NPIS emerged as vital for self-transcendence in the present results as well as in the literature [57, 105-108], and is found to boost global wellbeing [29, 48]. Consequently, nurse-patient interaction might influence on $\mathrm{NH}$ residents' wellbeing; physically, emotionally, socially, functionally and spiritually.

Former studies have shown that $\mathrm{NH}$ residents emphasize the nurses' attitudes, appearance and behaviours $[108,109]$, to act as a confirmation of their worthiness or worthlessness [31, 110,111]. Connectedness in a trusting nurse-patient relationship reduce anxiety and depressive symptoms [112], and facilitate feelings of being valuable, safe and cared for. Such experiences provide meaning-in-life while facing the end of it. Along with competent pain and symptom management, the nature of the nurse-patient interaction in long-term $\mathrm{NH}$ 


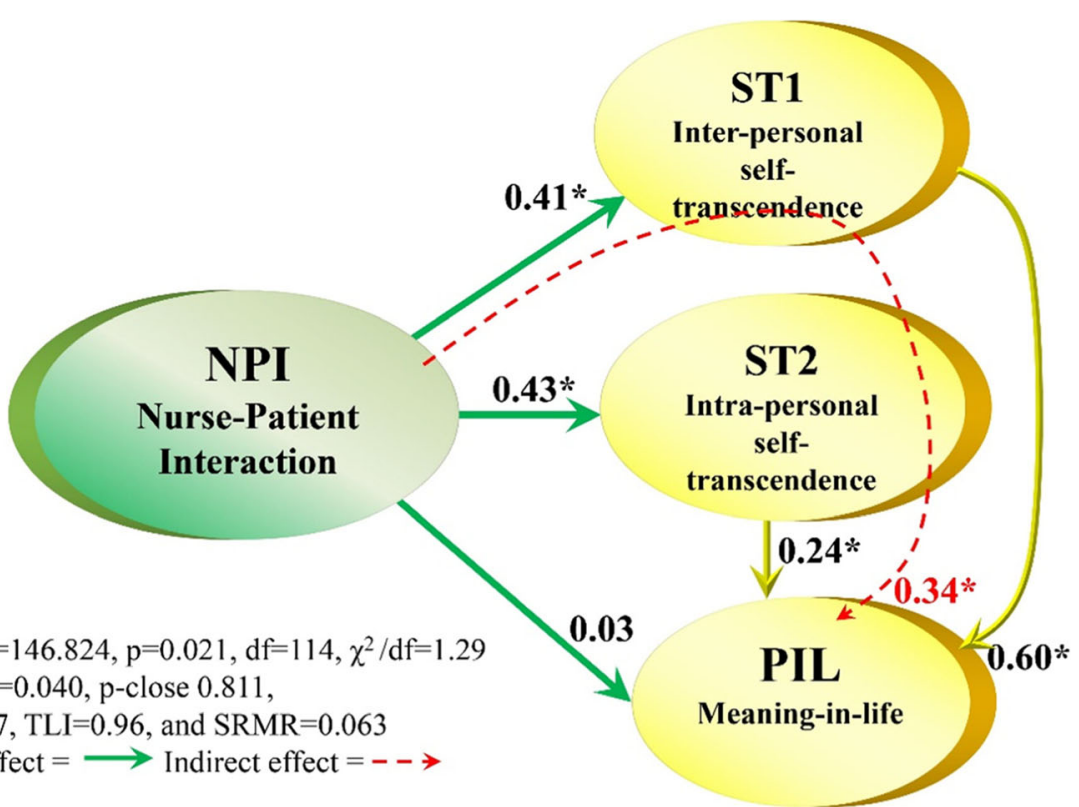

Fig. 2 The SEM-model testing the hypotheses H1-H6. Direct and indirect associations. ${ }^{*}$ significant at the $5 \%$ level

Table 3 SEM-model. Standardized Stata estimates of direct and indirect relationships and total effects of Nurse-Patient-Interaction (NPIS), on Self-Transcendence (ST1 and ST2) and Meaning-in-life (PIL)

\begin{tabular}{|c|c|c|c|}
\hline Construct & Parameter & & \\
\hline \multicolumn{4}{|c|}{ Direct relationships between NPIS and the dependent latent constructs } \\
\hline & & NPIS ${ }^{c}$ & \\
\hline \multirow[t]{2}{*}{$\mathrm{ST} 1^{\mathrm{d}}$} & $\gamma^{\mathrm{b}} 1,1$ & 0.41 & \\
\hline & $t$-value & $3.59^{\mathrm{a}}$ & \\
\hline \multirow[t]{2}{*}{$\mathrm{ST} 2^{\mathrm{e}}$} & Y 1,2 & 0.43 & \\
\hline & t-value & $4.37^{\mathrm{a}}$ & \\
\hline \multirow[t]{2}{*}{$\mathrm{PIL}^{\mathrm{f}}$} & Y 1,3 & 0.031 & \\
\hline & t-value & 0.27 & \\
\hline \multicolumn{4}{|c|}{ Indirect ${ }^{\mathrm{h}}$ (mediated) relationship between NPIS and PIL } \\
\hline & & NPIS & TOTAL EFFECT ${ }^{\mathrm{i}}$ \\
\hline \multirow[t]{2}{*}{ PIL } & y 1,3 & 0.34 & 0.37 \\
\hline & t-value & $3.13^{\mathrm{a}}$ & $3.13^{\mathrm{a}}$ \\
\hline \multicolumn{4}{|c|}{ Direct relationships between the dependent latent constructs } \\
\hline & & PIL & \\
\hline \multirow[t]{2}{*}{ ST1 } & $\beta^{9} 1,2$ & 0.60 & \\
\hline & t-value & $3.47^{\mathrm{a}}$ & \\
\hline \multirow[t]{2}{*}{ ST2 } & $\beta 3,5$ & 0.24 & \\
\hline & t-value & $2.10^{\mathrm{a}}$ & \\
\hline
\end{tabular}

${ }^{\mathrm{a}}$ Significant at the $5 \%$ level. Listwise $N=180$, Missing $N=8$. ${ }^{\mathrm{b}} \mathrm{Gamma}(\gamma)$; standardized regression coefficients representing directional relationships between ${ }^{\mathrm{c}} N P I S$ Nurse-Patient-Interaction and ${ }^{\mathrm{d}} S T 1$ Interpersonal Self-Transcendence, ${ }^{e}$ ST2 Intrapersonal self-transcendence and ${ }^{\mathrm{f}} P I L$ Meaning-in-life). ${ }^{\mathrm{g}}$ Beta $(\beta)$ standardized regression coefficients representing directional relationships between ST1, ST2 and PIL. " Indirect effects represent the influence of NPIS mediated by intervening variables (mediators). 'Total Effect represent the total influence of the explanatory variable NPIS (direct + indirect effects) 
care is crucial. Frustration, suffering, hopelessness, meaninglessness and depression result from not being attended to or treated with indifference, and thereby violating individuals' sense of worthiness [113, 114] which negatively impact residents' mental and physical symptoms or ailments $[29,112]$.

Possibly, older adults' self-acceptance and thereby their sense of self-worth and value can be strengthened by active listening, recognizing and empowering the uniqueness of this person whose subjective experiences are taken seriously and respected, all of which supporting global wellbeing. If older adults' in $\mathrm{NHs}$ feel understood, acknowledged, confirmed, and valued by their nurses, self-transcendence, and meaning will increase; consequently, gratefulness and wellbeing redoubles. However, the accomplishment of such a health-promoting nurse-patient interaction requires caregivers who are willing to and competent in engaging with their residents in different ways, such as learning about the person through life histories [115-118], listening to their life experiences, wisdom, dreams and frightens. Professional nursing care is determined by the way nurses use their knowledge, attitudes, behaviour, and communication skills to appreciate the uniqueness of the person being cared for [118-120].

\section{The interrelations between self-transcendence and meaning}

The second research question aimed at investigating the inter-relationships between the constructs of inter- and intra-personal self-transcendence and meaning-in-life. The latter is often seen to be an explicit goal of $\mathrm{NH}$ care in Norway [29, 31, 121]. If looking at the total and indirect effects, interpersonal self-transcendence (ST1) showed a great influence on meaning-in-life; ST1 includes being involved with others and the society, having hobbies or interests and sharing one's wisdom with others [50]. This finding is in line with a longitudinal study by Norberg and her colleagues (2015) of 190 oldest-old individuals in Sweden; self-transcendence was significantly related to wellbeing overall. Moreover, studies among $\mathrm{NH}$ residents in Taiwan and Norway have disclosed a negative association with depressive symptoms [122, 123] and a positive association with wellbeing [48]. Also, Hoshi [124] found a mediated effect of selftranscendence on the relationship between vulnerability and wellbeing in 105 Japanese hospitalized elders. Accordingly, facilitating these aspects among $\mathrm{NH}$ residents will increase meaning-in-life, and consequently wellbeing. Furthermore, intrapersonal self-transcendence (ST2) involving self-acceptance, adapting well to this specific life situation and one's functionality, displayed a significant impact on meaning. Research reveals that self-transcendence reduces stress, enhances wellbeing, hope and meaning among several patient groups facing the vulnerability of serious, progressive disease including multiple sclerosis and systemic lupus erythematosus [125], older women living with rheumatoid arthritis [126] as well as among individuals with spinal muscular atrophy [127] and amyotrophic lateral sclerosis [128]. Also, self-transcendence has been used to design programs effective in promoting successful aging among older adults in the community $[129,130]$. This indicates that supporting self-acceptance and adaption to one's life situation will support meaning among older adults in NHs. The various aspects of self-transcendence seemed to be forceful vitalities, revealing significant influences on meaning-in-life, which represents an essential goal for $\mathrm{NH}$ care.

\section{Strengths and limitations}

A notable strength of this research is the empirical examination of associations of various constructs that are scarcely elucidated. This study expands previous research by testing the associations between nurse-patient interaction, self-transcendence and meaning-in-life in an $\mathrm{NH}$ population utilizing structural equation modeling. The SEM measurement technique includes estimates for random measurement error, thus the involved measurement models (here models for NPI, ST1, ST2 and PIL) are more precisely derived. The study builds on a strong theoretical foundation with the use of scales demonstrating good psychometrical properties. Nevertheless, the present findings must be discussed with some limitations in mind.

The SEM-model tested comprises 17 variables, indicating a desirable sample size of minimum $N=170$ [69-71]. In the present study listwise $\mathrm{N}$ was 180, which should be enough. Still, a larger sample would significantly strengthen the statistical power of the tests. Information input to the SEM estimation increases both with more indicators per latent variable, and with more sample observations. More indicators per latent variable would have strengthened the composite reliability and the Cronbach's $\alpha$ but weakened the statistical power. Therefore, with reference to sample size we reduced the indicators for each of the latent constructs. Nevertheless, composite reliability was acceptable to good, with ST1 (three items), showing the lowest reliability.

The cross-sectional design of this study implies that we cannot make conclusions on the causality. That is, we cannot define the direction of the paths with certainty [70]. Feasibly, the latent variable performs both as a predictor and an outcome of another construct. Despite a good fit, some alternative model might possibly fit better or be more accurate. However, the fit indices and 
composite reliability underpin the present results. There was also no problem with discriminant and convergent validity as we found good factor loadings indicating that the theoretical plausibility was good; all paths corresponded well to the theoretical basis, which supports the findings.

The fact that the researchers visited the participants to help fill in the questionnaires might have introduced some bias into the respondents' reporting. The three scales used were part of a larger questionnaire comprising nine scales and 120 items. Thus, frail, older $\mathrm{NH}$ residents might tire when completing the questionnaires, representing a possible bias to their reporting. To avoid such a bias, experienced researchers were carefully selected and trained in conducting the interviews following a standardized procedure including taking small breaks at specific points during the process. Moreover, the order of the scales might affect the participants' reporting; in this study demographics were collected firstly, followed by symptom burden, joy-of-life, loneliness (one item), sense of coherence, ST, PIL, NPI, anxiety and depression, and global QoL. This order was used in every interview, including a 5 minutes break between ST and PIL to avoid tiring the respondent. Since residents with dementia, as well as short time stay and rehabilitation residents were excluded in this study, the present results cannot be generalized to the entire $\mathrm{NH}$ population.

\section{Implications to nursing practice}

The results of this study accentuate that a holistic and person-centered care based in a health-promoting nurse-patient interaction is recommended $[115,116$, 131]. However, NH staff members in general are not well trained in nurse-patient-interaction. There is a need of educational nursing curricula emphasizing knowledge about and training in nurse-patient interaction as a resource for wellbeing, mediated by self-transcendence and meaning. Also, $\mathrm{NH}$ caregivers should be provided further education and support [132-134]. Appropriate learning programs facilitating health professionals' interacting skills should be employed along with assessing their usefulness $[135,136]$. Additionally, NH staff members have limited time along with an experience of minor autonomy in their job performance. Research discloses that health professionals in NHs communicate a need to feel respected and cared for by the management [137-140]. To provide compassionate, attentive, and sensitive health care, a working culture characterized by a caring and respecting management [141, 142]. Hence, to facilitate self-transcendence and meaning, a sound and health-promoting working culture should be facilitated and nurtured [143, 144]. Both $\mathrm{NH}$ residents and
$\mathrm{NH}$ staff will benefit from transforming the traditional institutional model of care into a responsive, patientcentered, homelike approach [131].

\section{Conclusion}

This study indicates that nurse-patient-interaction directly relates to $\mathrm{NH}$ residents' inter- and intrapersonal self-transcendence and meaning-in-life. It seems obligatory that high-quality nurse-patient-interaction should be developed to foster $\mathrm{NH}$ residents' sense of worthiness, self-acceptance, adjustment, and connectedness, as these might foster self-transcendence, meaning-in-life and thereby wellbeing. The NHs should be developed so that the staff nurses have more time for interacting with their residents; continuity and mutuality in nurse-patient relationships should be prioritized and facilitated.

\section{Abbreviations \\ $x^{2}$ : Chi-square; a: Cronbach's alpha reliability coefficient; $\rho c$ : Composite Reliability coefficient; CFI: Comparative Fit Index; JoLNH: A nursing home which is certified as a Joy-of-Life Nursing Home; $\mathrm{NH}$ : Nursing home; QoL: Quality of life; MSc: Academic degree Master; NPI: Nurse-Patient Interaction; NPIS: Nurse-Patient Interaction Scale; PIL: The questionnaire termed "Purpose-In-Life test" assessing perceived meaning-in-life; RN: Registered Nurse; RMSEA: Root Mean Square Error of Approximation; SEM: Structural Equation Modelling; SD: Standard Deviation; SRMS: Standardized Root Mean Square Residual; ST: Self-Transcendence; STS: Self-Transcendence Scale; ST1: Inter-personal Self-Transcendence; ST2: Intra-personal Self-Transcendence; TLI: Tucker Lewis Index}

\section{Acknowledgments}

The authors want to acknowledge the nursing home residents who voluntarily participated in this study.

\section{Authors' contributions}

All authors (GH, BMK, WME, SET, ER, VXW, JD \& BA) made substantial contributions to conception and design, or acquisition of data, or analysis and interpretation of data, and were involved in drafting the manuscript or revising it critically for important intellectual content. All authors read and approved the manuscript.

\section{Funding}

This study received funding from the Norwegian Council of Research, which had no role in this study.

\section{Availability of data and materials}

The datasets generated and/or analysed during the current study are not publicly available due to Norwegian Act on medical and health research (ACT 2008-06-20 no. 44):§ 38 but are available from the corresponding author on reasonable request. All raw data is in Norwegian.

\section{Ethics approval and consent to participate}

Ethical approval was obtained by the Regional Committee for Medical and Health Research Ethics in Norway (ref.nr 2014/2000/REK Central) as well as by the Management Units at the 27 nursing homes which participated in this study. The participants provided voluntarily written informed consent.

\section{Consent for publication}

Not applicable.

\section{Competing interests}

The authors declare no conflict of interest.

\section{Author details}

${ }^{1}$ Department of Public Health and Nursing, Faculty of Medicine and Health Science, NTNU Norwegian University of Science and Technology, Trondheim, 
Norway. ${ }^{2}$ NORD University, Faculty of Nursing and Health Science, Levanger, Norway. ${ }^{4}$ Trondheim Municiaplity, Trondheim, Norway. ${ }^{3}$ Faculty of Health and Social Science, Western University of Applied Science, Bergen, Norway. ${ }^{5}$ Alice Lee Centre for Nursing Studies, Yong Loo Lin School of Medicine, The National University of Singapore, Singapore, Singapore. ${ }^{6}$ Department of Global Health and Primary Care, University of Bergen, Bergen, Norway.

\section{Received: 2 March 2020 Accepted: 13 April 2020}

\section{Published online: 07 May 2020}

\section{References}

1. Kinsella K, He W. An Aging World: 2008. Washington, DC: Department of Health and Human Services National Institutes of Health NATIONAL INSTITUTE ON AGIN U.S. Department of Commerce Economics and Statistics; 2009. Contract No.: Report No.: P95/09-1.

2. HOD MoHacs. The primary health and care services of tomorrow: localized and integrated. St.Meld.26 2014-2014. Oslo: Ministry of Health and Care Services $\mathrm{N}$; 2015

3. WHO. Ageing and health: World Health Organization; 2018. https:/www. who.int/news-room/fact-sheets/detail/ageing-and-health. updated 2018, February 5 th.

4. Modig K, Virtanen S, Ahlbom A, Agahi N. Stable or improved health status in the population 65 years and older in Stockholm, Sweden - an 8-year follow-up of self-reported health items. Scand J Public Health. 2016;44(5):480-9.

5. Kingston A, Wohland P, Wittenberg R, Robinson L, Brayne C, Matthews F, et al. Is late-life dependency increasing or not? A comparison of the cognitive function and ageing studies (CFAS). Lancet. 2017;390:1676-84.

6. World Health Organization. Aging and global health; 2011. https://www. who.int/ageing/publications/global_health.pdf.

7. Kelly A, Conell-Price J, Covinsky K, Cenzer IS, Chang A, Boscardin WJ, et al. Length of stay for older adults residing in nursing homes at the end of life. J Am Geriatr Soc. 2010;58(9):1701-6.

8. Vossius C, Selbæk G, Šaltyte Benth J, Bergh S. Mortality in nursing home residents: A longitudinal study over three years. PloS one. 2018;13(9): e0203480.

9. Temkin-Greener $\mathrm{H}$, Zheng NT, Xing J, Mukamel DB. Site of death among nursing home residents in the United States: changing patterns, 2003-2007. J Am Med Dir Assoc. 2013;14(10):741-8.

10. Barca ML, Selbæk G, Laks J, Engedal K. Factors associated with depression in Norwegian nursing homes. Int J Geriatr Psychiatry. 2009;24(4):417-25.

11. Haugan G. Meaning-in-life in nursing-home patients: a correlate to physical and emotional symptoms. J Clin Nurs. 2014;23(7-8):1030-43.

12. Drageset J, Eide G, Ranhoff A. Depression is associated with poor functioning in activities of daily living among nursing home residents without cognitive impairment. J Clin Nurs. 2011;20(21-22):3111-8.

13. Goud AA, Nikhade NS. Prevalence of depression in older adults living in old age home. IAIM. 2015;2(11):1-5.

14. Xia N, Li H. Loneliness, social isolation, and cardiovascular health. Antioxid Redox Signal. 2018;28(9):837-51.

15. Liu L, Gou Z, Zou J. Social support mediates loneliness and depression in elderly people. J Health Psychol. 2016;21(5):750-8.

16. Sanderson WC, Scherbov S. Demography. Remeasuring aging. Science. 2010;329(5997):1287-8.

17. Steptoe A, Deaton A, Stone AA. Subjective wellbeing, health, and ageing. Lancet. 2015;385(9968):640-8.

18. Man-Ging Cl, Uslucan JÖ, Frick E, Büssing A, Fegg MJ. Meaning in life of older adults living in residential and nursing homes. J Relig Spiritual Aging 2019;31(3):305-22.

19. Thauvoye E, Vanhooren S, Vandenhoeck A, Dezutter J. Spirituality among nursing home residents: a phenomenology of the experience of spirituality in late life. J Religion Spirituality Aging. 2019;32:88-103.

20. Angel S. The fight for a meaningful life [Danish]. Sygeplejersken Danish J Nurs. 2009;109(17):48-53.

21. Hedberg P, Brulin C, Aléx L, Gustafson Y. Purpose in life over a five-year period: a longitudinal study in a very old population. Int Psychogeriatr. 2011;23(5):1p.

22. Martela F, Steger MF. The three meanings of meaning in life: distinguishing coherence, purpose, and significance. J Posit Psychol. 2016;1 1(5):531-45.

23. Kane R. Definition, measurement, and correlates of quality of life in nursing homes: Toward a reasonable practice, research, and policy agenda. Gerontologist. 2003;43(2):28.
24. Czekierda K, Banik A, Park CL, Luszczynska A. Meaning in life and physical health: systematic review and meta-analysis. Health Psychol Rev. 2017;11(4): 387-418.

25. Duppen D, Machielse A, Verté D, Dury S, De Donder L, Consortium D-S. Meaning in life for socially frail older adults. J Community Health Nurs. 2019; 36(2):65-77.

26. Daaleman TP, Williams CS, Hamilton VL, Zimmerman S. Spiritual care at the end of life in long-term care. Med Care. 2008;46(1):85-91.

27. Fegg MJ, Kogler M, Abright C, Hensler M, Lorenzl S. Meaning in life in patients with progressive Supranuclear palsy. Am J Hosp Palliat Care. 2013; 31(5):543-7.

28. Fegg M, Kogler M, Brandstatter M, Jox R, Anneser J, Haarmann-Doetkotte S, et al. Meaning in life in patients with amyotrophic lateral sclerosis. Amyotroph Lateral Scler. 2010;11(5):569-74.

29. Haugan G. Meaning-in-life in nursing-home patients: a valuable approach for enhancing psychological and physical well-being? I Clin Nurs. 2014; 23(13-14):1830-44.

30. Mwilambwe-Tshilobo L, Ge T, Chong M, Ferguson M, Misic B, Burrow A, et al. Loneliness and meaning in life are reflected in the intrinsic network architecture of the brain. Soc Cogn Affect Neurosci. 2019;14(4):423-33.

31. Drageset J, Haugan G, Tranvåg O. Crucial aspects promoting meaning and purpose in life: perceptions of nursing home residents. BMC Geriatrics. 2017; 17(1):254.

32. Rinnan E, Andrè B, Drageset J, Garåsen H, Espnes GA, Haugan G. Joy of life in nursing homes: a qualitative study of what constitutes the essence of joy of life in elderly individuals living in Norwegian nursing homes. Scand J Caring Sci. 2018:32:1468-76.

33. Phillips-Salimi CR, Haase JE, Kooken WC. Connectedness in the context of patient-provider relationships: a concept analysis. J Adv Nurs. 2012;68(1):230-45.

34. Prieto-Flores M, Fernandez-Mayoralas G, Forjaz M, Rojo-Perez F, MartinezMartin P. Residential satisfaction, sense of belonging and loneliness among older adults living in the community and in care facilities. Health Place. 2011;17(6):1183-90.

35. Stavrova O, Luhmann M. Social connectedness as a source and consequence of meaning in life. J Posit Psychol. 2016;11(5):470-9.

36. Haugan $\mathrm{G}$. The relationship between nurse-patient-interaction and meaning-in-life in cognitively intact nursing-home patients. J Adv Nurs. 2014;70(1):107-20.

37. Tejero L, Marie $S$. The mediating role of the nurse-patient dyad bonding in bringing about patient satisfaction. J Adv Nurs. 2012;68(5):994-1002.

38. Burack OR, Weiner AS, Reinhardt JP, Annunziato RA. What matters Most to nursing home elders: quality of life in the nursing home. J Am Med Dir Assoc. 2012;13(1):48-53.

39. Reed PG. Theory of Self-Transcendence. In: Smith MJ, Liehr PR, editors. Middle Range Theory for Nursing. 2nd ed. New York: Springer Publishing Company, LLC; 2008. p. 105-29.

40. Reed PG. Theory of self-transcendence. In: Smith MJ, Liehr PR, editors. Middle range theory for nursing. 4th ed. New York: Springer Pub; 2018. p. $119-46$.

41. Erikson EH. Childhood and society. New York: W.W. Norton \& Company, Inc; 1950.

42. Coward DD, Reed PG. Self-transcendence: a resource for healing at the end of life. Issues Ment Health Nurs. 1996;17(3):275-88.

43. Neill J. Transcendence and transformation in the life patterns of women living with reumathoid arthritis. Adv Nurs Sci. 2002;24:27-47.

44. Nygren B, Aléx L, Jonsén E, Gustafson Y, Norberg A, Lundman B. Resilience, sense of coherence, purpose in life and self-transcendence in relation to perceived physical and mental health among the oldest old. Aging Ment Health. 2005;9(4):354-62.

45. Jones CS. Culture Change and Quality of Life in Elderly Persons Living in Long Term Care. UNF Graduate Theses and Dissertations. 2010:423. https:// digitalcommons.unf.edu/etd/423.

46. Baker CD. Self-transcendence, death anxiety, and older adult's participation in health promotion behaviours. Wisconsin: University of Wisconsin; 2008.

47. Cooney A, Dowling M, Gannon M, Dempsey L, Murphy K. Exploration of the meaning of connectedness for older people in long-term care in context of their quality of life: a review and commentary. Int J Older People Nurs. 2014 9(3):192-9.

48. Haugan G, Rannestad T, Hammervold R, Garåsen H, Espnes GA. Selftranscendence in nursing home patients - a resource for well-being. J Adv Nurs. 2013;69(5):1147-60. 
49. Haugan G. The FACIT-Sp spiritual well-being scale: an investigation of the dimensionality, reliability and construct validity in a cognitively intact nursing home population. Scand J Caring Sci. 2015;29(1):152-64.

50. Haugan G, Rannestad T, Garåsen H, Hammervold R, Espnes GA. The selftranscendence scale - an investigation of the factor structure among nursing home patients. J Holist Nurs. 2012;30(3):147-59.

51. Haugan G, Hanssen B, Rannestad T, Espnes GA. Self-transcendence and nurse-patient interaction in cognitively intact nursing-home patients. J Clin Nurs. 2012;21:3429-41.

52. Haugan G, Moksnes U. Meaning-in-life in nursing-home patients: a validation study of the purpose-in-life test. J Nurs Meas. 2012;21:296-319.

53. Seligman MEP. Flourish: a visionary new understanding of happiness and well-being. New York: Simon and Schuster; 2012.

54. Starck PL. The theory of meaning in hospice care. Korean J Hosp Palliat Care. 2017:20(4):221-5.

55. Haugan G, Eide WM, André B, Xi WV, Rinnan E, Taasen SE, Kuven BM \& Drageset, J. Joy-of-Life in cognitively intact Nursing Home Patients: the Impact of the Nurse-Patient Interaction. Scand J Caring Sci; 2020. https://doi. org/10.1111/scs.12836.

56. Hodge DR, Horvath VE. Spiritual needs in health care settings: a qualitative meta-synthesis of Clients' perspectives. Soc Work. 2011;56(4):306-16.

57. Slettebo A, Saeteren B, Caspari S, Lohne V, Rehnsfeldt AW, Heggestad AKT, et al. The significance of meaningful and enjoyable activities for nursing home resident's experiences of dignity. Scand J Caring Sci. 2017;31(4):71826.

58. Haugan G. Self-transcendence, well-being and nurse-patient interaction in cognitively inatct nursing home patients [PhD]. Trondheim: Norwegian University of Science and Technology; 2013.

59. Haugan G. Nurse-patient interaction is a resource for hope, meaning-in-life, and self-transcendence in cognitively intact nursding-home patients. Scand J Caring Sci. 2014;2014(28):74-8.

60. Carpenter K, Girvin L, Kitner W, Ruth-Sahd L. Spirituality. A Dimension of Holistic Critical Care. Dimens Crit Care Nurs. 2008;27(1):16-22.

61. Kirby SE, Coleman PG, Daley D. Spirituality and well-being in frail and nonfrail older adults. J Gerontol B Psychol Sci Soc Sci. 2004;59B(3):P123-9.

62. Baldacchino D. Spiritual care: being in doing. Malta: Preca Library; 2010.

63. Boyle P, Barnes L, Buchman A, Bennett D. Purpose in life is associated with mortality among community-dwelling older persons. Psychosom Med. 2009; 71:574-9.

64. Krause N. Meaning in life and mortality. J Gerontol B Psychol Sci Soc Sci. 2009;64B(4):517-27.

65. Thompson $\mathrm{P}$. The relationship of fatigue and meaning in life in breast cancer survivors. Oncol Nurs Forum. 2007;34(3):653-60.

66. Baldacchino D. Spirituality in illness and care. Malta: Preca Library; 2003.

67. Koenig HG. Religion, spirituality, and medicine: research findings and implications for clinical practice. South Med J. 2004;97(12):1194-200.

68. Kline R. Principles and practice of structural equation modeling. 2nd ed. Kenny DA, editor. London: The Guilford Press; 2005.

69. Brown T. Confirmatory factor analysis for applied research. New York: The Guilford Press; 2006.

70. Jj H, Black W, Babin B, Anderson R. Multivariate data analysis. Upper Saddle River: Prentice Hall; 2010.

71. Schumacker R, Lomax R. A Beginner's guide to structural equation modeling. New York-London: Psychology Press - Taylor \& Francis Group; 2004.

72. Haugan G, Rinnan E, Espnes GA, Drageset J, Rannestad T, André B. Development and psychometric properies of the Joy-of-Life Scale in cognitively intact nursing home patients. Scand J Caring Sci. 2019;33:801-14.

73. Haugan G, Drageset J, André B, Kukulu K, Mugisha J, Utvær BKS. Assessing quality of life in older adults: psychometric properties of the OPQoL-brief questionnaire in a nursing home population. Health Qual Life Outcomes. 2020;18:1.

74. Haugan G, Eide Wenche M, André B, Wu X, Vivien, Rinnan E, Taasen S, Kuven BM, Drageset J. Joy-of-life in cognitively intact nursing home patients: the impact of the nurse-patient interaction. Scand J Caring Sci. 2020. https://doi.org/10.1111/SCS.12836.

75. Reed PG. Developmental resources and depression in the elderly. Nurs Res. 1986;35:368-74.

76. Reed PG. Nursing: The Ontology of the Discipline. In: Reed PG, Shearer NBC, editors. Perspectives on Nursing Theory. 5th Edition ed. Philadelphia Baltimore - New York - London - Buenos Aires - Hong Kong - Sydney Tokyo: Wolters Kluwer: Lippincott Williams \& Wilikns; 2009. p. 615-20.
77. Reed PG. Self-transcendence and mental health in oldest-old adults. Nurs Res. 1991;40:5-11.

78. Runquist JJ, Reed PG. Self-transcendence and well-being in homeless adults. J Holist Nurs. 2007;25(1):5-13.

79. Reker $\mathrm{G}$. Theoretical perspectives, dimensions and measurement of existential meaning. In: Reker G, Chamberlain K, editors. Exploring existential meaning: Optimising human development across the life span. USA: Sage; 2000. p. 39-55.

80. Steger MF, Frazier P, Oishi S, Kaler M. The meaning in life questionnaire: assessing the presence of and search for meaning in life. J Couns Psychol. 2006;53:80-93.

81. Frazier P, Oishi S, Steger M. Assessing optimal human functioning. In: Walsh W, editor. Counseling psychology and optimal human functioning. Mahwah: Erlbaum; 2003. p. 251-78.

82. Crumbaugh JC, Maholick LT. An experimental study in existentialism: the psychometric approach to Frankl's concept of noogenic neurosis. J Clin Psychol. 1964;20(2):200-7.

83. Crumbaugh JC, Maholick LT. Manual of Instructions for The Purpose-in-life test. Psychometric Affilitates. Viktor Frankl Institute of Logotherapy P.O.Box 2852, Saratoga, CA 95070) Murfreesboro, TN: Psychometric Affiliates: 1. Crumbaugh, J.C., Maholick, L.T. (1969) Manual of instructions for the purpose-in-life test. Illinois: Psychometric Affiliates; 1969, 1981.

84. Crumbaugh JC, Henrion R. The PIL test: administration, interpretation, uses theory and critique. Int Forum Logother. 1988;11(2):76-88.

85. Bondevik M. The life of the oldest old. Studies concerning loneliness, social contacts, activities of daily living, purpose in life and religiousness. Bergen: University of Bergen; 1997.

86. Sheth K. Relationships between percveived meaning in life and death anxiety in the elderly. Masters Abstr Int. 1990;29(2):209.

87. Bondevik M, Skogstad A. Loneliness, religiousness, and purpose in life in the oldest old. J Relig Gerontol. 2000;11(1):5-21.

88. Flood M, Scharer K. Creativity enhancement: possibilities for succesful aging. Issues Ment Health Nurs. 2006;27:939-59.

89. StataCorp. Stata 15 Base Reference Manual. 2017.

90. Raykov T. Estimation of congeneric scale reliability using covariance tructure analysis with nonlinear constraints. Br J Math Stat Psychol. 2001;54(2):315-23.

91. Sharma S. Applied multivariate techniques. New York: Wiley; 1996.

92. Schermelleh-Engel K, Moosbrugger $\mathrm{H}$, Muller $\mathrm{H}$. Evaluating the fit of structural equation models: tests of significance and descriptive goodnessof-fit measures. Methods Psychol Res. 2003;8(2):23-74.

93. Jøreskog K, Sørbom D. LISREL 8: structural equation modeling with the SIMPLIS command language. Chicago: Scientific Software International; 1995.

94. Jøreskog K, Sørbom D, du Toit S, du Toit M. New statistical features. Chicago: Scientific Software International, Inc.; 2000.

95. Vandenberg RJ. Statistical and methodological myths and urban legends. Organ Res Methods. 2006;9(2):194-201.

96. Hu L, Bentler P. Fit indices in covariance structure modeling: sensitivity to Underparametrized model Misspesification. Psychol Methods. 1998;3(4):424-53.

97. Nunally JC, Bernstein IH. Psychometric theory. New York: McGraw-Hill; 1994.

98. Dwyer L, Nordenfelt L, Ternestedt B-M. Three nursing home residents speak about meaning at the end of life. Nurs Ethics. 2008;15(1):97-109.

99. Harrefors C, Sävenstedt S, Axelsson K. Elderly people's perceptions of how they want to be cared for: an interview study with healthy elderly couples in northern Sweden. Scand J Caring Sci. 2009;23(2):353-60.

100. Heliker D, Hoang TN. Story sharing: enhancing nurse aide-resident relationships in long-term care. Res Gerontol Nurs. 2010;3(4):240-52.

101. Annear M, Elliott K, Tierney L, Lea E, Robinson A. "Bringing the outside world in": Enriching social connection through health student placements in a teaching aged care facility. Health Expect. 2017;20(5):1154-62.

102. Shipley S. Listening: a concept analysis. Nurs Forum. 2010;45(2):125-34.

103. Björk S, Lindkvist M, Lövheim $H$, Bergland $\AA$, Wimo A, Edvardsson D. Exploring resident thriving in relation to the nursing home environment: $A$ cross-sectional study. J Adv Nurs. 2018;74(12):2820-30.

104. Nakrem S, Vinsnes AG, Seim A. Residents' experiences of interpersonal factors in nursing home care: a qualitative study. Int J Nurs Stud. 2011;48(11):1357-66.

105. Svanström $R$, Johansson Sundler A, Berglund M, Westin L. Suffering caused by care-elderly patients' experiences in community care. Int J Qual Stud Health Well Being. 2013;8:20603.

106. Sheridan NF, Kenealy TW, Kidd JD, Schmidt-Busby J, Hand JE, Raphael DL, et al. Patients' engagement in primary care: powerlessness and compounding jeopardy. A qualitative study. Health Expect. 2015;18(1):32-43. 
107. Finch LP. Nurses' communication with patients: examining relational communication dimensions and relationship satisfaction. Int J Hum Caring. 2005;9(4):14-23

108. Finch LP. Patients' communication with nurses: relational communication and preferred nurse behaviors. Int J Hum Caring. 2006;10(4):14-22.

109. McGilton KS, Boscart VM. Close care provider-resident relationships in longterm care environments. J Clin Nurs. 2007;16(11):2149-57.

110. Lundgren SM, Berg L. The meanings and implications of receiving care. Scand J Caring Sci. 2011;25(2):235-42.

111. Hedelin B, Jonsson I. Mutuality as background music in women's lived experience of mental health and depression. J Psychiatr Ment Health Nurs. 2003;10(3):317-22.

112. Haugan G, Innstrand ST, Moksnes UK. The effect of nurse-patient-interaction on anxiety and depression in cognitively intact nursing home patients. J Clin Nurs. 2013;22(15-16):2192-205.

113. Jonas-Simpson C, Mitchell GJ, Fisher A, Jones G, Linscott J. The experience of being listened to: a qualitative study of older adults in long-term care settings. J Gerontol Nurs. 2006;32(1):46-53.

114. Botngård A, Eide AH, LMosqueda L, Malmedal W. Elder abuse in Norwegian nursing homes: a cross-sectional exploratory study. BMC Health Serv Res. 2020:20(9):1-12.

115. Medvene LJ, Lann-Wolcott H. An exploratory study of nurse aides' communication behaviours: giving 'positive regard' as a strategy. Int J Older People Nursing. 2010;5(1):41-50.

116. Wright K. Prevention and treatment of depression in care homes. Nurs Res Care. 2010;12(4):188-91.

117. Kieft RA, de Brouwer BB, Francke AL, Delnoij DM. How nurses and their work environment affect patient experiences of the quality of care: a qualitative study. BMC Health Serv Res. 2014;14:249.

118. Yang Y, Li H, Xiao LD, Zhang W, Xia M, Feng H. Resident and staff perspectives of person-centered climate in nursing homes: a cross-sectional study. BMC Geriatr. 2019;19(1):292.

119. Warelow P, Edward KL, Vinek J. Care: What nurses say and what nurses do. Holist Nurs Pract. 2008;22(3):146-53.

120. Lood Q, Kirkevold M, Sjögren K, Bergland $\AA$, Sandman P, Edvardsson D. Associations between person-centred climate and perceived quality of care in nursing homes: A cross-sectional study of relatives' experiences. J Adv Nurs. 2019;75:2526-34

121. Haugland $B \varnothing$. Meningsfulle aktiviteter på sykehjemmet [Meaningful activities in nurisng homes]. Sykepleien Forskning. 2012;7(1):42-9.

122. Hsu Y-C, Badger T, Reed P, Jones E. Factors associated with depressive symptoms in older Taiwanese adults in a long-term care community. Int Psychogeriatr. 2013;25(06):1013-21.

123. Haugan G, Innstrand ST. The effect of self-transcendence on depression in cognitively intact nursing home patients. ISRN Psychiatry. 2012;2012:301325

124. Hoshi M. Self-transcendence, vulnerability, and well-being in hospitalized Japanese elders. Tucson: University of Arizona; 2008.

125. Iwamoto R, Yamawaki N, Sato T. Increased self-transcendence in patients with intractable diseases. Psychiatry Clin Neurosci. 2011;65:638-47.

126. Neill J. Transcendence and transformation in the life patterns of women living with rheumatoid arthritis. Adv Nurs Sci. 2002;24(4):27-47.

127. Ho H-M, Tseng Y-H, Hsin Y-M, Chou F-H, Lin W-T. Living with illness and self-transcendence: the lived experience of patients with spinal muscular atrophy. J Adv Nurs. 2016;72(11):2695-705.

128. Fanos JH, Gelinas DR, Foster RS, Postone N, Miller RG. Hope in palliative care: from narcissism to self-transcendence in amyotrophic lateral sclerosis. J Palliat Med. 2008;11(3):470-5.

129. McCarthy VL, Ling J, Bowland SE, Hall LA, Connelly J. Promoting selftranscendence and well-being in community-dwelling older adults: a pilot study of a psychoeducational intervention. J Geriatric Nurs. 2015;36(6):431-7.

130. McCarthy VL, Hall LA, Crawford TN, Connelly J. Facilitating selftranscendence: an intervention to enhance well-being in late life. West J Nurs Res. 2018;40(6):854-73.

131. Jones CS. Person-centered care: The heart of culture change. J Gerontol Nurs. 2011;37(6):18-25

132. Hov $R$, Athlin $E$, Hedelin B. Being a nurse in nursing home for patients on the edge of life. Scand J Caring Sci. 2009;23(4):651-9.

133. McGilton KS, Boscart V, Fox M, Sidani S, Rochon E, Sorin-Peters R. A systematic review of the effectiveness of communication interventions for health care providers caring for patients in residential care settings. Worldviews Evid-Based Nurs. 2009;6(3):149-59.
134. Levy-Storms $L$. Therapeutic communication training in long-term care institutions: recommendations for future research. Patient Educ Couns. 2008; 73(1):8-21.

135. Baldacchino D. Teaching on spiritual care: the perceived impact on qualified nurses. Nurse Educ Pract. 2011;11:47-53.

136. Baldacchino D. Teaching on the spiritual dimension in care to undergraduate nursing students: the content and teaching methods. Nurse Educ Today. 2008;28:550-62.

137. Castle N, Anderson R. Caregiver staffing in nursing homes and their influence on quality of care: using dynamic panel estimation methods. Med Care. 2011:49(6):545-52.

138. Castle N, Engberg J. The influence of staffing characteristics on quality of care in nursing homes. Health Serv Res. 2007:45(2):1822-47.

139. Caspar S, O'Rourke N. The influence of care provider access to structural empowerment on individualized care in long-term care facilities. J Gerontol B Psychol Sci Soc Sci. 2008;63(4):S255-S65.

140. Bishop C, Squillance M, Meagher J, Anderson W, Wiener J. Nursing home work practices and nursing assistants' job satisfaction. Gerontologist. 2009; 49(5):611-22.

141. Sikma S. Staff percepyions of caring: the importance of a supportive environment. J Gerontol Nurs. 2006;32(6):22-9.

142. Tellis-Nayak V. A person-centered workplace: the foundation for personcentered caregiving in long-term care. J Am Med Dir Assoc. 2007;8(1):46-54

143. André B, Sjøvold E, Rannestad T, Ringdal Gl. The impact of work culture on quality of care in nursing homes - a review study. Scand J Caring Sci. 2013; 28:449-57.

144. Jones CS. Culture change and quality of life in elderly persons living in long term care: University of North Florida; 2010.

\section{Publisher's Note}

Springer Nature remains neutral with regard to jurisdictional claims in published maps and institutional affiliations.

Ready to submit your research? Choose BMC and benefit from:

- fast, convenient online submission

- thorough peer review by experienced researchers in your field

- rapid publication on acceptance

- support for research data, including large and complex data types

- gold Open Access which fosters wider collaboration and increased citations

- maximum visibility for your research: over $100 \mathrm{M}$ website views per year

At $\mathrm{BMC}$, research is always in progress.

Learn more biomedcentral.com/submissions 